\title{
The Perceived Stress Reactivity Scale For Adolescent Athletes: Translation, Adaptation, Validity and Reliability Study
}

\author{
Ender ŞENEL ${ }^{1}$, Mevlüt YILDIZ², Nazmi BAYKÖSE³ \\ 1-Mŭ̆la Sıtkı Koçman Üniversitesi Spor Bilimleri Fakültesi, Beden Ĕ̆itimi ve Spor Öğretmenliği, Muğla endersenel@gmail.com \\ 2- Muğla Sıtkı Koçman Üniversitesi Spor Bilimleri Fakültesi, Antrenörlük Eğitimi, Muğla mevlutyildizz@gmail.com \\ 3- Akdeniz Üniversitesi Spor Bilimleri Fakültesi, Antrenörlük Eğitimi, Antalya nazmibaykose@gmail.com
}

\begin{abstract}
This study aims to analyze the validity and reliability of The Perceived Stress Reactivity Scale for Adolescent Athletes. 220 athletes including 111 females and 109 males from seventeen different sports branches participated in the study. The age mean of the participants was found to be $19.76 \pm 1.05$. The sporting age mean was found to be $7.11 \pm 2.96$. Data was collected by using The Perceived Stress Reactivity Scale for Adolescent Athletes (8), Perceived Stress Scale $(9,11)$. The factor structure was analyzed by using Confirmatory Factor Analysis in AMOS. Pearson Correlation test was used to analyze factor-factor relationship and criterion-related validity. The method of translation-back translation was used for the translation of the scale into Turkish. The results of the factor analysis displayed that 5 -factor model had acceptable fit indices ( $\mathrm{CFI}=.83, \mathrm{SRMR}=.07, \mathrm{RMSEA}=.07)$. The 5 -factor scale including the subscales of prolonged reactivity, reactivity to work overload, reactivity to social conflict, reactivity to social evaluation, and reactivity to failure had the same factor structure in Turkish athletes. Consequently, it can be said that The Turkish form of the Perceived Stress Reactivity Scale for Adolescent Athletes is valid and reliable.
\end{abstract}

Keywords: Adolescent athletes, scale adaptation, stress reactivity.

\section{INTRODUCTION}

The intense success pressure and high-level of stress and emotional distress among adolescents have been frequently seen in media and popular culture (28). The sports competition context in which success pressure is experienced intensively includes some factors causing stress at different levels for all age groups. Performance or mental errors, doing a mistake resulting in a serious punishment, being rebuked by the coach, coach's choice, discontent input from opponent, audience or teammate, and the stress stemming from the opponent's successful performance can be shown as the stressors in sport $(1,2,3,14,29)$. When faced with a stressor, the autonomous nerve system and the initial activation of hypothalamic-hypophysis-adrenal axis prepare the individual for the action and facilitate the processes of evaluation and coping reactions (8). The researchers have argued that stress is an ongoing operation between the environmental demands and the resources of the individual, and provided the "strain" concept resulting from the imbalance between these demands and the resources (20).

Competition stress and emotions have been explained in Lazarus' Cognitive-MotivationalRelational Theory $(17,18,19)$, it is suggested that an individual is more likely to experience negative emotions when lacking the resources to cope with the faced demands in the competition context (23). Lazarus and Folkman (21) argued that an evaluation of stressor consisted of many judgments related to the difficulty and threat to the individual, potential damage or benefit, and the perceived control.

The concept of coping, which is a complicated, intentional and generally planned psychological process and in accord with social context and its behavioral standards, contrary to innate action 
tendencies, focuses on the evaluation for what is possible, becomes effective in particular setting (17), is the process for the management of the individual's demands of individual-environment relations evaluated as stressful. This process includes cognitive and behavioral efforts spent to manage particular internal and external demands $(20,21)$. It has been found that athletes use various coping strategies $(1,24)$. According to Lazarus' theory, there are three types of coping strategies including problem-, emotion-, and avoidanceoriented strategies (21). While emotion-oriented coping aims to regulate emotions associated with stress condition, avoidance-oriented coping aims at steering away from the source of the problem. In problem-oriented coping, the individual collects information about what to do by aiming to change the reality in the problematic individualenvironment relation (18).

Coping can reduce stress reactions with the actions changing the actual relationship between individual and environment (problem-oriented), or by changing only the meaning of the relation $(13,18$, $20)$. The ability to cope with stressors during sports competitions is an inseparable part of the successful performance (15). Researchers have revealed that stressors negatively affect the performance $(2,3,4)$ and that undesirable emotion can arise when there are inadequate coping with stressors $(5,6,19,24)$. However, Lazarus (19) suggested that the sense of anxiety could be beneficial for performance, with an increase in activated energy and focus on the existing task.

Determining the reaction of adolescent athletes to stressors can help coaches, trainers, parents, and athletes to adjust proper and adequate coping strategies. However, there is no measurement tool to assess the reactivity against stressors in the sports context in Turkish literature. This study aims to analyze the validity and reliability of The Perceived Stress Reactivity Scale for Adolescent Athletes.

\section{MATERIALS \& METHOD}

\section{Participants}

The athletes competing in different sports branches were recruited (111 females, 109 males). The age mean was $19.76 \pm 1.05$. The athletes trained approximately for $2.27 \pm .96$ hours per day, $3.57 \pm .80$ day per week. They reported to have been competing for $7.11 \pm 2.96$ years on an average.
Preliminary study included 30 athletes including 15 females and 15 males. The age mean of the participants in preliminary study was 19.06 \pm 1.19 . Most of the athletes participated in this study reported that they have been competing in amateur leagues $(77.7 \%)$.

\section{Measurements}

The Perceived Stress Reactivity Scale for Adolescent Athletes (PSRS-AA): Britton, Kavanagh, and Polman (8) developed the 5-factor scale. The original scale consists of 23 items and includes five sub-scales. Each item has three specific responds between zero (0) and two (2). Zero represents the lowest reactivity while two reflects the highest. The sum of each sub-scale reveals the reactivity of athletes. The instruction of the original scale was designed for athletes to reflect the reaction against stressors in the sports participation, rather the stressors faced generally. The instruction of this study was designed in this direction.

Perceived Stress Scale: The criterion related validity was tested by correlating PSRS-AA with PSS, developed by Cohen, Kamarck, and Mermelstein (9), translated into Turkish by Eskin, Harlak, Demirkıran and Dereboy (2013). The scale consists of 14 items rated between 1 (never) and 5 (very often).

\section{Translation Process}

The scale was translated by following the stages suggested by Beaton et al. (7) for conceptualization of self-report measures for cross-cultural adaptation studies and the steps of translation were as follows: synthesis, back translation, expert committee evaluation, pretesting, and submitting the measure to the developers or coordination committee for evaluation. Since there was no coordination committee and developer evaluation in this study, five basic steps were followed. Author permission was asked and after the permission was granted, the translation process started. Two translators-one was informed and aware of the concepts (T1) and another was neither informed nor aware of the concepts (T2)-translated the items into Turkish (Stage 1). Two academicians having studies into sport psychology examined both translations (T1 and T2) and created a synthesis form (Stage 2), which was used for back translation. The synthesis form was created after examining the items translated in T1 and T2. Two academicians, both 
were neither informed nor aware of the concepts, translated the synthesis form (T12) into English (Stage 3). Five academics, working in the field of sport sciences, knowing English and Turkish very well, evaluated the T1, T2, T12, BT1, and BT2 versions in terms of equivalences of semantic, idiomatic, experiential, and conceptual (Stage 4). After considering the suggestion and corrections, the Turkish form of the inventory was ready for the pretesting (Stage 5).

\section{Data Collection}

Researchers collected the data in the second term of the 2017-2018 season. They explained the purpose of the study in detail and guaranteed that all of the responses kept secret and used for scientific goals.

\section{Statistical Analysis}

Data was analyzed in SPSS $®$ statistics (version 22) software and $\mathrm{AMOS}^{\mathrm{TM}}$. The analyses for demographic information and features were done by using descriptive statistics. The factor structure was analyzed with Confirmatory Factor Analysis (CFA). CFA is a proper method for testing the explored and theory-based models (12, 16, 30). Kaiser-Meyer-Olkin (KMO) and Bartlett's Test of Sphericity values were calculated to determine whether the data was proper for the factor analysis. The fit of the hypothesized models to data was evaluated through chi square value (significance level $\mathrm{a}=0.05)$, degrees of freedom, comparative fit index (CFI), standardized root mean residual (SRMR), root mean square error of approximation (RMSEA). The mean score and standard deviation of the students' ratings was calculated in excel. The scores were shown in the Figure 1. Content validity index for item (I-CVI) and scale (S-CVI) were calculated in excel (see Table 1). Polit and Beck (25) defined the content validity as the degree to which an instrument has an appropriate sample of items for the construct being measured. To calculate the ICVI, the number of agreement among the experts was calculated for each item. I-CVI was calculated by dividing number of agreement by number of experts. The mean score of I-CVIs shows the S-CVI (26). Pearson Correlation test was used to analyze factor-factor relationship and criterion-related validity.

\section{FINDINGS}

Figure 1. The means and standard deviations of items from the Turkish form of PSRS-AA

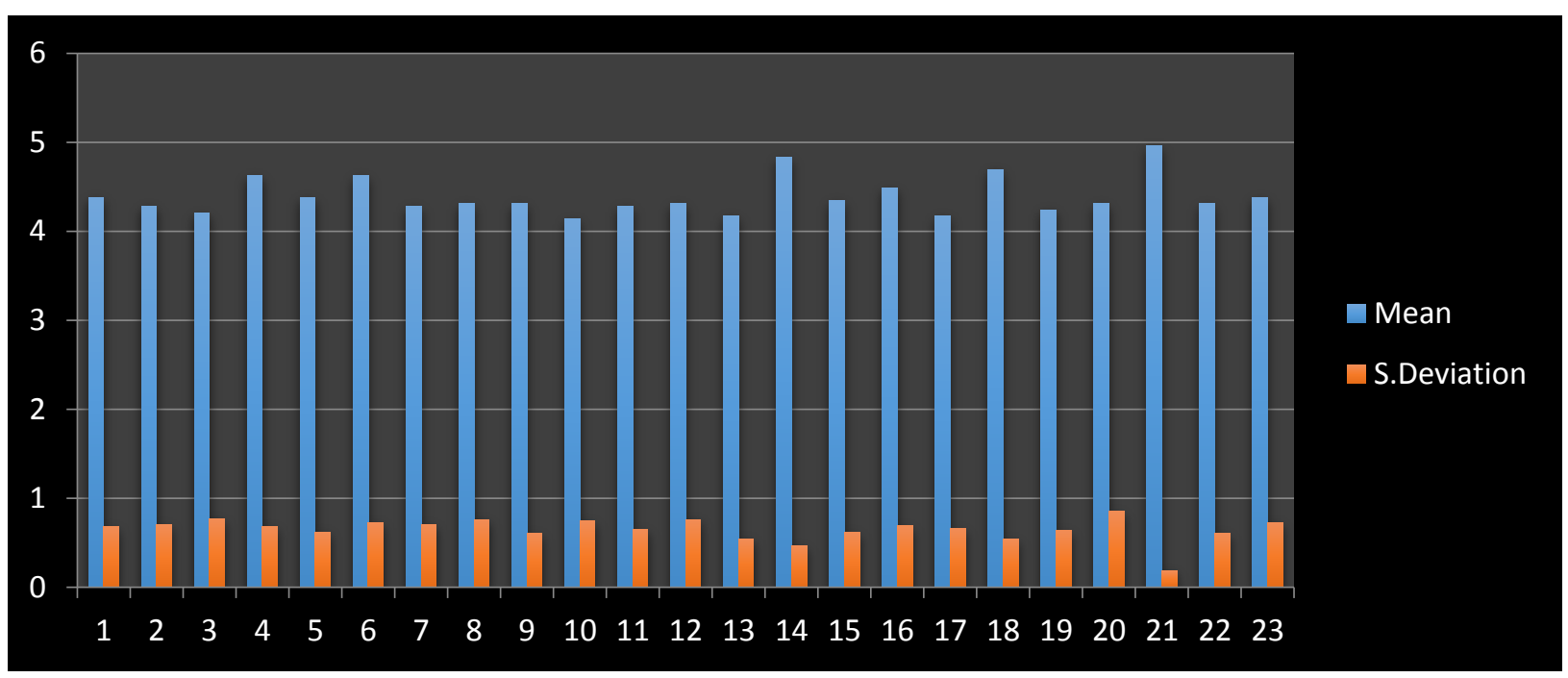

Figure 1 presents the mean scores and standard deviation of the extent to which the student-athletes understand each item of the new Turkish version of the PSRS-AA. The mean scores are between 4 and 5, which means that the items are understandable. 
Table 1. The Content Validity Indexes

\begin{tabular}{|c|c|c|c|c|c|c|c|c|}
\hline Item & Expert 1 & Expert 2 & Expert 3 & Expert 4 & Expert 5 & Expert 6 & Number of agreement & I-CVI \\
\hline 1 & 4 & 4 & 4 & 4 & 4 & 4 & 6 & 1 \\
\hline 2 & 4 & 4 & 3 & 3 & 4 & 4 & 6 & 1 \\
\hline 3 & 4 & 3 & 3 & 4 & 4 & 4 & 6 & 1 \\
\hline 4 & 4 & 4 & 4 & 4 & 4 & 3 & 6 & 1 \\
\hline 5 & 3 & 4 & 3 & 4 & 3 & 3 & 6 & 1 \\
\hline 6 & 3 & 4 & 4 & 4 & 4 & 4 & 6 & 1 \\
\hline 7 & 4 & 4 & 4 & 3 & 3 & 4 & 6 & 1 \\
\hline 8 & 4 & 3 & 3 & 3 & 4 & 3 & 6 & 1 \\
\hline 9 & 3 & 3 & 3 & 3 & 3 & 2 & 5 & 0,83 \\
\hline 10 & 3 & 4 & 4 & 4 & 4 & 3 & 6 & 1 \\
\hline 11 & 4 & 4 & 4 & 4 & 4 & 4 & 6 & 1 \\
\hline 12 & 4 & 4 & 3 & 2 & 4 & 4 & 5 & 0,83 \\
\hline 13 & 4 & 4 & 4 & 4 & 4 & 3 & 6 & 1 \\
\hline 14 & 4 & 4 & 4 & 4 & 4 & 4 & 6 & 1 \\
\hline 15 & 3 & 4 & 4 & 4 & 4 & 3 & 6 & 1 \\
\hline 16 & 3 & 4 & 4 & 4 & 4 & 2 & 5 & 0,83 \\
\hline 17 & 3 & 4 & 4 & 4 & 3 & 4 & 6 & 1 \\
\hline 18 & 4 & 3 & 3 & 3 & 4 & 4 & 6 & 1 \\
\hline 19 & 3 & 4 & 4 & 4 & 4 & 4 & 6 & 1 \\
\hline 20 & 4 & 4 & 4 & 4 & 4 & 4 & 6 & 1 \\
\hline 21 & 4 & 4 & 4 & 4 & 4 & 4 & 6 & 1 \\
\hline 22 & 4 & 3 & 4 & 4 & 4 & 4 & 6 & 1 \\
\hline 23 & 4 & 4 & 4 & 4 & 4 & 3 & 6 & 1 \\
\hline & & & & & & \multicolumn{2}{|r|}{ S-CVI/Ave } & 0,97 \\
\hline & & & & & & \multicolumn{2}{|r|}{ Total Agreement } & 20 \\
\hline $\begin{array}{c}\text { Proportion } \\
\text { relevant }\end{array}$ & 1.0 & 1.0 & 1.0 & .95 & 1.0 & .91 & S-CVI/UA & 0,86 \\
\hline
\end{tabular}

Table 1 represents the content validity indexes calculated after the expert ratings. In line with our results, Beaton et al. (7) suggested that the responses and answers to the interview ensured that the adapted version maintained the equivalences. Participants rated how well they understood each item by scoring between 0 and 4 . In this study, experts were asked to rate the relevance of each item to perceive stress reaction against the stressors in sport (26). As it was advised (10, 32), six experts rated the items between 1 and 4 . The I-CVI values were not lower than 0.78 (21), and these results were acceptable. S-CVI/Ave and S-CVI/UA were found to be as 0.97 and 0.86 , respectively, and this result is also acceptable $(10,26)$. S-CVI and I-CVI scores were calculated, and the results showed that the content of the inventory was valid.

The CFA revealed that the 5-factor model had acceptable fit indexes (CFI=.83, SRMR=.07, RMSEA=.07). It was found that the factor structure of the original scale including PrR, RWO, RSC, RFa, and RSE displayed the same structure in Turkish athletes. The factor loads ranged between 0.43 and 0.70 . Cronbach's alpha internal consistency values of subscales ranged between 0.60 and 0.75 while composite reliability ranged between 0.59 and 0.77 . The internal consistency value of the whole scale was 0.89 . The correlation between the subscales and perceived stress showed that the Turkish form of the scale was a valid structure. 
Table 2. 5-Factor model solution, factor-factor correlations, criterion-related validity, and CFA fit indexes of Turkish version of PSRS-AA

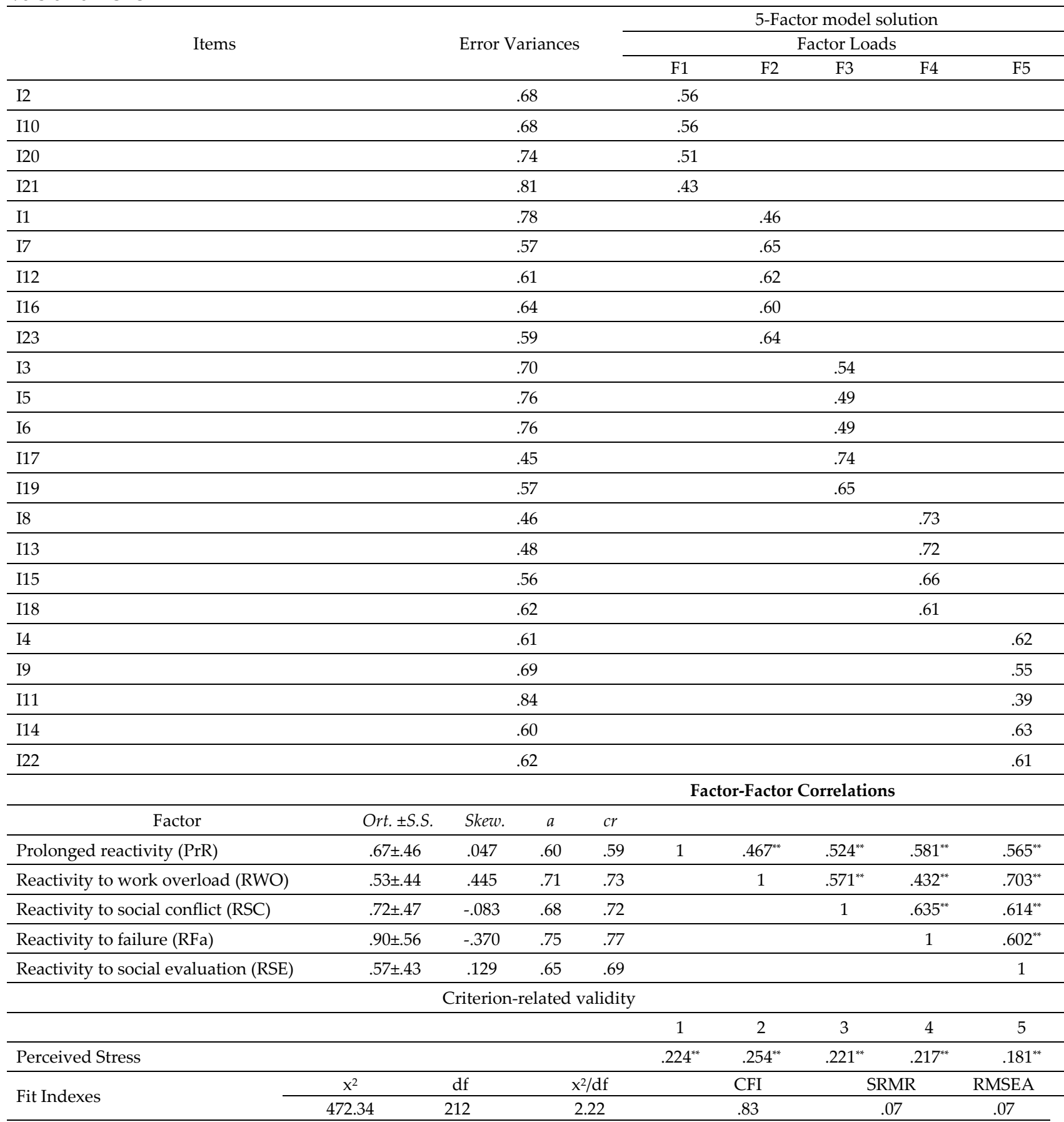

\section{DISCUSSION \& CONCLUSION}

This study aimed to translate the PSRS-AA into Turkish and conduct the initial structure analysis. In line with the suggestion by Beaton et al. (7) for the adaptation of self-report measurements, the items were translated into Turkish. In the preliminary study, the scores of the athletes on the items showed that the items are understandable, and the experts' opinions revealed that the scale and its items are valid according to content validity indexes. I-CVI values were not lower than 0.78 , and these results are at an acceptable level (22). S-CVI was found to be 0.94, and this result was also acceptable (10). The preliminary analysis showed that the initial version of the scale was understandable and fit for the athletes. By using CFA to test the structure of an explored model, the factor structure of the Turkish version of PSRS-AA was analyzed. CFA is a more convenient method for testing previously discovered theoretical-based models $(12,16)$. For the reliability of the scale, the internal consistency 364 
coefficient, as well as the composite reliability analysis, was performed. When the errors of measurements positively correlated, the alpha coefficient can overestimate the true reliability of a composite (27). Thurber and Bonynge (31) suggest that calculating composite reliability is a more

\section{REFERENCES}

1. Anshel M. Coping styles among adolescent competitive athletes. The Journal of Social Psychology, 1996; 136(3): 311323.

2. Anshel $\mathrm{MH}$, Kaissidis AN. Coping style and situational appraisals as predictors of coping strategies following stressful events in sport as a function of gender and skill level. British Journal of Psychology, 1997; 88(2): 263-276.

3. Anshel MH, Wells B. Sources of acute stress and coping styles in competitive sport. Anxiety, Stress and Coping, 2000; 13(1): $1-26$.

4. Anshel MH, Brown JM, Brown DF. Effectiveness of program for coping with acute stress on motor performance, affect, and muscular tension. Australian Journal of Science and Medicine in Sport, 1993; 25: 7-16.

5. Barnett LA. Flying high or crashing down: Girls' accounts of trying out for cheerleading and dance. Journal of Adolescent Research, 2006; 21: 514-541.

6. Barnett LA. "Winners" and "losers": The effects of being allowed or denied entry into competitive extracurricular activities. Journal of Leisure Research, 2007; 39(2): 316-344.

7. Beaton, D. E., Bombardier, C., Guillemin, F., \& Ferraz, M. B. (2000). Guidelines for the process of cross-cultural adaptation of self-report measures. Spine, 25(24), 3186-3191.

8. Britton D, Kavanagh E, Polman R. The Perceived Stress Reactivity Scale for adolescent athletes. Personality and Individual Differences, 2017; 116: 301-308.

9. Cohen S, Kamarck T, Mermelstein R. A global measure of perceived stress. Journal of Health and Social Behavior, 1983, 24(4): 385-396.

10. Davis LL. Instrument review: Getting the most from your panel of experts. Applied Nursing Research, 1992; 5(4): 194197.

11. Eskin M, Harlak H, Demirkıran F, Dereboy Ç. Algılanan stres ölçeğinin Türkçeye uyarlanması: güvenirlik ve geçerlik analizi. New Symposium Journal, 2013; 51(3): 132-140.

12. Fabrigar L.R, Wegener DT, MacCallum RC, Strahan EJ. Evaluating the use of exploratory factor analysis in psychological research. Psychological methods, 1999; 4(3): 272-299

13. Folkman S, Lazarus RS. An analysis of coping in a middleaged community sample. Journal of Health and Social Behavior, 1980; 21(3): 219-239.

14. Goyen MJ, Anshel MH. Sources of acute competitive stress and use of coping strategies as a function of age and gender. Journal of Applied Developmental Psychology, 1998, 19(3): 469-486.

15. Hardy L, Jones G, Gould D. Understanding psychological preparation for sport: Theory and practice of elite performers. John Wiley and Sons, New York, 1996.

16. Hurley AE, Scandura TA, Schriesheim CA, Brannick MT, Seers A, Vandenberg RJ, Williams LJ. Exploratory and confirmatory factor analysis: Guidelines, issues, and alternatives. Journal of Organizational Behavior, 1997; 18(6): 667-683.

Turk ل Sport Exe 2019; 21(2): 360-365

๑ 2019 Faculty of Sport Sciences, Selcuk University proper method. Both alpha and composite reliability scores displayed that the scale was reliable. Consequently, these results indicate that the Turkish version of PSRS-AA is valid and reliable structure to use in the Turkish population.

17. Lazarus RS. Emotion and adaptation. Oxford University Press, New York, 1991

18. Lazarus RS. Stress and emotion: A new synthesis. Springer Publishing, 1999

19. Lazarus RS. How emotions influence performance in competitive sports. The Sport Psychologist, 2000; 14(3): 229252.

20. Lazarus RS, Folkman, S. Stress, appraisal, and coping. New York: Springer, 1984.

21. Lazarus RS, Folkman S. Transactional theory and research on emotions and coping. European Journal of Personality, 1987; 1(3): 141-169.

22. Lynn MR. Determination and quantification of content validity. Nursing Research, 1986; 35(6): 382-385.

23. Neil, R., Hanton, S., Mellalieu, S. D., \& Fletcher, D. (2011). Competition stress and emotions in sport performers: The role of further appraisals. Psychology of sport and exercise, 12(4), 460-470.

24. Nicholls AR, Polman R. Coping in sport: A systematic review. Journal of Sports Sciences, 2007; 25(1): 11-31.

25. Polit DF, Beck CT. Nursing research: Principles and methods. Lippincott Williams \& Wilkins, 2004.

26. Polit DF, Beck CT. The content validity index: are you sure you know what's being reported? Critique and recommendations. Research In Nursing \& Health, 2006; 29(5): 489-497.

27. Rae G. Correcting Coefficient Alpha for Correlated Errors: Is a $\mathrm{K}$ a Lower Bound to Reliability? Applied Psychological Measurement January, 2006; 30(1): 56-59.

28. Spencer R, Walsh J, Liang B, Mousseau AMD, Lund TJ. Having it all? A qualitative examination of affluent adolescent girls' perceptions of stress and their quests for success. Journal of Adolescent Research, 2018; 33(1): 3-33.

29. Taylor J, Ogilvie B. A conceptual model of adaptation to retirement among athletes. Journal of Applied Sport Psychology, 1994; 6(1): 1-20.

30. Thompson B. Exploratory and confirmatory factor analysis: Understanding concepts and applications. American Psychological Association. Washington DC, 2004.

31. Thurber S, Bonynge M. SEM-based composite reliability estimates of the Crisis Acuity Rating Scale with children and adolescents. Archives of Assessment Psychology, 2011; 1(1): $1-9$

32. Waltz CF, Bausell RB. Nursing Research: Design, Statistics, and Computer Analysis. F. A. Davis: Philadelphia, FA, USA, 1981. 